\title{
Digital play for language development in the early grades
}

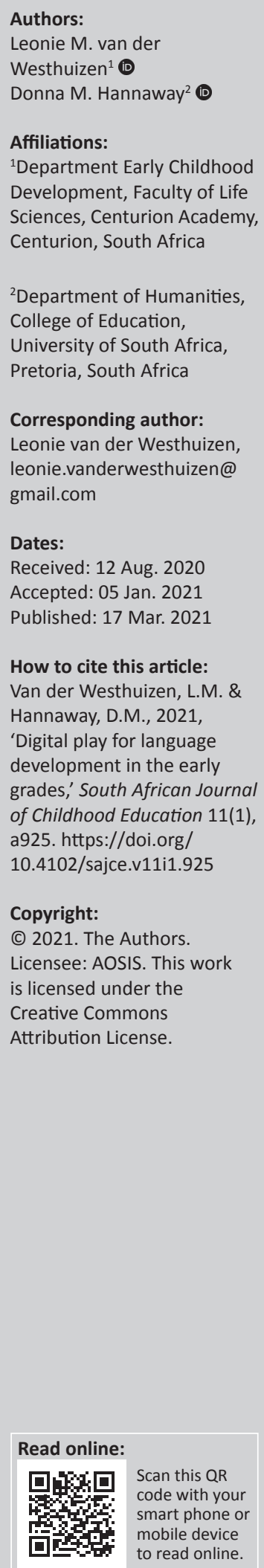

Background: The digital world and the concomitant changes in early childhood education have created uncertainty for teachers not knowing how to adjust their pedagogical practices of using digital play to enhance language development.

Aim: This study aimed to analyse what teachers understand by digital play and how they use it for language teaching in the early grades, with specific reference to the reception year.

Setting: The researcher chose a primary school in an urban area that had digital technology available in the classroom involving eight Grade R teachers.

Methods: Semi-structured questionnaires and focus group interviews were used to collect data on how teachers interact with learners using digital technology. Non-participatory observations of these interactions were also noted. Data analysis considered teacher views about the role of information communication technology (ICT) in education, digital games, and the extent to which digital pedagogies can enhance language acquisition.

Results: The analysis found that the teachers are willing to experiment with digital games. However, there is a need to understand more about digital technology and increase their knowledge on using digital games when teaching language. Teachers shared the view that digital games should, as is the case with traditional play-based pedagogies, be used to enhance language teaching as this generation is growing up in a digital environment.

Conclusion: It was clear that the emphasis needs to be on the development of games, which use digital technology relevant to language teaching. Furthermore, the findings suggest that those pedagogies that use digital games relevant to the Digital Era be adopted. There is a need for further enquiry into teachers' beliefs and digital literacy and practices in more diverse settings to further understand the value of digital play in language teaching.

Keywords: digital play; Grade R learners; language acquisition; early childhood; digital technology; information communication technology; teacher pedagogical beliefs.

\section{Introduction}

The 21st century is known as the Digital Era, or the Fourth Industrial Revolution, which means that 'our devices will become an increasing part of our personal ecosystem, listening to us, anticipating our needs, and helping us when required' (Schwab 2017:11). Children are constantly connected to various digital devices and these often regulate their lives. Thus, teachers need to embrace and incorporate digital technology into their teaching approaches so that young learners acquire language proficiency early (Dietze \& Kashin 2013:5).

However, this is a challenge for teachers, as they have to understand how to incorporate digital technology into their usual teaching practices. Examples include various digital devices, tools, applications and processes, which facilitate knowledge learning and teach learners to be more creative (Berson \& Berson 2010:192). Therefore, teachers need to be skilled in the use of digital technology and need to create digital solutions to problems (Murcia, Campbell \& Aranda 2018:251). Various authors, such as Edwards, Straker and Oakey (2018) and Murcia et al. (2018), state that in both the formal and informal environments, social inclusivity and learning are improved with the use of digital technology.

Digital teaching is defined by Murcia et al. (2018:251) as 'any type of teaching that is facilitated by technology or by instructional practice that makes effective use of technology'. According to these authors, digital technologies may also include 'social media, online games and applications, multimedia, productivity applications, cloud computing, interoperable systems and mobile 
devices' (Murcia et al. 2018:251). In the Digital Era, children are presented with a physical, social and cultural world where they learn and interact digitally (ed. Arnott 2017:8).

Traditional early childhood teaching methods rely mostly on resources such as storybooks and toys (Parette \& Blum 2013:126). However, in this digital generation of wired learners, traditional games and books are still relevant and should be balanced with activities using technology. Technology does change the ways in which children play and can aid their learning experiences (Dietze \& Kashin 2013:2). The focus on literacy development in early childhood education means that current practices of language teaching need research-based evidence regarding the efficacy of the inclusion of digital play pedagogies.

Pedagogies of play have proven to be valuable in early childhood education (Arnott 2016:273). Jensen et al. (2019:24) highlighted that although play forms an important part of teaching practices in the early years, the implementation thereof is problematic. Classes are too large because of the high admission rates of 5- and 6-year-olds, teachers are not well trained, and there are insufficient guidelines for the various programmes. Jensen et al. (2019:24) stated that although play-based learning should be the norm, traditional teaching methods using books and tried and tested practices are the determining factors of pedagogical practices, and teachers view play as being only what happens when the learners are out of the classroom during breaks.

Multimedia and computer-based print create a more inclusive definition of literacy according to Berschorner and Hutchinson (2013:17) and need to supplement and enhance methods to teach reading and writing. Bers (2018) also argued for a pedagogy of digital play and recommended that teachers carefully devise experiences for the learners who are playful. Bers (2018) advocated for a pedagogical approach where digital technology is a tool that can facilitate and add to the learning experience. The essential role that digital technology has is a blueprint for understanding the digital word; one which 'has the potential to be a much richer learning environment for young learners' (Berson \& Berson 2010:9).

Teachers should consider that young learners create meaning and construct knowledge through play and do not only receive information passively. The curriculum in Grade $\mathrm{R}$ in South Africa for language teaching is built on the fundamentals of integrating learning, which is based on play, in line with Curriculum Assessment Policy Statements (CAPS) (Department of Basic Education [DBE] 2011:20). As language learning is a complicated issue comprising a multitude of factors including contextualisation, it is critical to be aware of how to build that foundation of language skills needed, and to understand how these language skills enable learners to develop successful relationships with peers and elders.

Including language lessons in the classroom that are based on play is a fundamental issue in pedagogical methods, as these contribute to the Grade $\mathrm{R}$ learners' language skills.
Given the value of play pedagogies in the early grades, this researcher argues for the use of digitally based pedagogies for language teaching, and poses the question: How do teachers incorporate digital play in their teaching practices for language learning?

\section{Literature review}

The reality is that a large segment of children is immersed in a digital world, and digital games have the potential to enhance language teaching. This is not the case for all children in South Africa as the digital divide is wide and access to digital devices and data limited. This empirical study explored how teachers understand and use digital play. It is widely accepted that technology forms and underwrites early childhood educational practices. Arnott, Palaiologou and Gray (2019:405) stated that 'the child is the expert in their own digital play' where they understand apparent differences in play in the social world, they live in. Arnott emphasises that digital play is like all types of play, more so if mixed with traditional pedagogies. Digital play should not be the dominant factor of play. Digital technology is but one factor of the present preschool system (Arnott 2016:287). In our South African context, digital play can be included with success if the necessary resources, such as tablets and applicable line digital games, are available.

Digital play in an online playground involves creating a fun virtual world with 'multiple learners standing in close proximity to the resource and attempting to take part in some way, even if not physically controlling the technology' (Arnott 2016:277). Such an experience is assumed to elicit a multitude of social behaviours, which determine the way learners interact with the technology (Arnott 2016:279). In South Africa, the situation is more complicated as there is a digital divide because of, inter alia, poverty that constricts the access to devices and data. In a study in the Harmony Early Childhood Center, in the Olathe Unified School District, Donohue and Schomburg (2017:72) found that digital play assists children's learning and development, as demonstrated in a classroom activity called 'The Journalist'. The teacher takes on the role of a journalist, snapping pictures with a tablet and documenting the activities of the learners. Then a picture is projected onto a wall or screen for all to see, and the learners discuss it. Communication skills, for example, the learner's recall of a story, or the ability to answer a question, can then be judged.

In a 2-day workshop in Hong Kong, a group of nine children aged 5-8 years, used film-language to share their toy-playing stories and make their own 1-min video through play (Leung, Choi \& Yuen 2020). This shows that digital tools may be useful for integrating digital technologies into children's play in the early childhood education curriculum. Another study shows how digital games such as 'ScratchJr', which was launched in July 2014 by Mitch Resnick and his team at the Massachusetts Institute of Technology (MIT) Media Lab, significantly improve the child's ability to put picture stories into a logical sequence (Bers 2018:116). 
In the Global North it became evident that young learners treat digital media and real toys in similar ways, and the manipulation of images on a digital device can be seen as symbolic play (Brooker \& Siraj-Blatchford 2002, as quoted by Arnott 2016:272). Children no longer access only traditional paper-based means when drawing and writing; they are also able to obtain photographs, videos, audio clips, graphics, and so on, which they either use on their own or mix with traditional methods (McGlynn-Stewart et al. 2018:42).

Teachers develop their pedagogies of play through experience, drawing on the more traditional Reggio Emilia (Mayesky 2014:87) and Maria Montessori (Mayesky 2014:172) approaches, and thus have difficulty in adjusting to the use of technology. Often, they are not familiar with the digital devices, which can be used in the classroom, for example, how to use video making to guide children to make use of storyboards to tell their stories (Leung et al. 2020). Thus, the pedagogies they apply are trial and error, seeking to find the appropriate technology. Arnott's Digital Play Framework (2016:271) can help the teacher to understand where technology fits into the learners' play as it shows many of the behaviours the young exhibit whilst using digital technology in play, including those technologies with a screen, such as computers and tablets. However, that does not help the teachers with their insecurities about how to use digital technologies in the classroom. Furthermore, some teachers need to overcome barriers when these technologies are introduced, whilst others are questioning the usefulness of including these digital technologies in their pedagogies (Marklund 2019).

Piaget and Vygotsky's theories are relevant for both traditional and digital pedagogies of play as these authors demonstrate that play is a crucial aspect of the development of young children (as quoted by Berson \& Berson 2010:5). According to Piaget, by the time a child is 2 years old, they can demonstrate and reconstruct their everyday experiences in three types of play: 'exploratory play' (e.g. devising new methods for goal achievement, 'functional play' (where they use the right tools and toys) and 'symbolic play' which is akin to make believe play (as quoted by Parette \& Blum 2013:204).

These types of play can be enabled using digital technology with the understanding that there will be access to digital devices and data. This, however, is a challenge in the Global South with the digital divide, poverty lines and access to devices and data. For example, in exploratory play, functional play is reflected in filling in blocks, deleting material, sorting and the repetition of patterns (e.g. on a tablet screen), and during symbolic play when they use their own creativity and their memories of photos or drawings of various objects. When Grade Rs are playing at make believe, the use of digital technology helps them to process their emotions as they can be somebody or something else and allows them to practise new social skills. In addition, they inculcate values and develop new language skills, adding to their rich imaginations (Parette \& Blum 2013:205).
Moreover, because digital technology is interactive and fascinating with all the visual and moving images, the teacher can scaffold instructions in their learning methods (Parette \& Blum 2013:124). Digital applications can thus be used to supplement a teaching approach which is based on play and can give the learners' easy instructions to follow (scaffolding) (McGlynn-Stewart et al. 2018:42).

The notion of scaffolding, according to Vygotsky, is important in aiding understanding how the youngsters acquire language, as they are empowered and prompted to understand what is being said or done (as quoted by Berson \& Berson 2010). Vygotsky's idea of a 'scaffolded pedagogical approach' is a co-construction of knowledge within learnercentred activities (as quoted by Gonzalez-Mena 2011:27). It is adult-driven and based on an understanding of teacherlearner interaction as a one-way process (as quoted by Gonzalez-Mena 2011:27). The scaffolding pedagogy can assist the learners and help them to understand and explain to each other what they learn in the process.

Bronfenbrenner's (1994:39-40) bio-ecological theory is important for this study because it offers the perspective that teaching and learning in schools comprises various systems, which have influence on the lives of both learners and teachers. Bronfenbrenner (1994) clarified that the child's environment comprises five systems of interaction: a microsystem, a mesosystem, an exosystem, a macrosystem and a chronosystem. In this study, the teacher is the central person (microsystem), but this is not limited to the teacher and includes other learners and the actual school. They all play an important role in supporting language acquisition in the learners through discussions, questions and clarification of events. In the mesosystem, the interaction between the various players in the microsystem, with their diversity, comes into play with the learners' prior digital knowledge of digital play and language acquisition. Parents at home can provide opportunities for digital technology to be included in the exosystem. They can be playing an instrumental role in reading and listening to stories on tablets, for example. The cultural and political environment of both teachers and learners is the macrosystem. During cultural activities the family participates in pretend play and performances can take place. The chronosystem comprises, for instance, the development of technology, including digital technology.

The five systems connect learners, teachers, the school environment and today's digital culture. Teachers' pedagogies, learners' experience with digital technology, and the availability of digital devices and applications are all interlinked.

\section{Research design and methods Design}

The inquiry into the understanding and beliefs of the Grade $\mathrm{R}$ teachers of using digital play in language teaching was conducted through an interpretative lens. Using a case study as the research design, the research involved all the early 
childhood teachers in one primary school, including the head of department. The selected school is situated in an urban area, and had digital technology, such as tablets and computers available for the Grade R classes. The teachers booked the digital centre and took the class to use the digital technology provided by the school. Using the guidelines for qualitative methods outlined by Creswell (1998:15), the data included a baseline focus group interview, a series of nonparticipant observations of teachers' lessons, eight semi-structured individual teacher interviews and a post-observation focus group interview.

\section{Procedure}

The data collection took place in four phases. Phase 1 was the preparation phase, where the design of the empirical study was finalised, and this included the participation selection process, the research plan and the development of the data generation instruments.

Phase 2 comprised the implementation of the data gathering plan and data were gathered from a focus group interview, non-participatory classroom observations, audio recordings, post-observation reflections and by means of semi-structured individual teacher's interviews, as well as a teacher group discussion (Yilmaz 2013:315). The teacher's methods of using digital technology play to aid language learning, and how they dealt with the learner's responses, were also analysed. The teacher's recommendations for others regarding using digital technology to aid language learning were also noted.

During phase 3, the audio recordings and interviews were transcribed (Flick 2018:335). In the last phase, the feedback phase, the main findings were given to those teachers who had participated and the Grade R Head of Department (HOD), as well as the Gauteng Department of Education and the management team of the school.

The analysis was guided by questions about current pedagogies of teaching using digital play for language teaching, how learners respond to such pedagogies and what recommendations could be made about the use of digital play to enhance language teaching. This involved coding and categorisation and the identification of themes (Creswell 1998:140). Thereafter, the data were displayed in diagrams, tables or graphs. A final overall analysis of the findings was developed after all the data sets had been coded and put into categories (Yilmaz 2013:320). The findings were triangulated to ensure that the data were accurately representative.

\section{Ethical consideration}

The participant teachers were told that they were voluntarily part of the research and had the option to discontinue the research at any time. Approval was given by the University of South Africa College of Education Ethics Review Committee (reference 2019/02/13/44582463/28/ $\mathrm{MC})$. Consent was negotiated with the Grade $\mathrm{R}$ teachers and the school principal.

\section{Findings}

The initial question posed for the research was: How do teachers understand and use digital play methods to enhance language teaching in Grade R? The findings were reported as follows: (1) the teachers' understanding of digital play, (2) how they use digital play methods, (3) the views held about the value of digital play and (4) play methods used for language learning.

\section{Teachers' understanding of digital play}

The initial focus group comprised of eight teachers and the discussion indicated that learners are quite comfortable with digital devices and constantly play games on them. Two of the teachers were observed using technology-based games as part of their lessons. Learners responded by immediately starting to use the tablets in the digital centre of the school. Other teachers used digital media such as PowerPoint and YouTube videos. Teachers shared the view during the semistructured individual interviews that they felt there was much more to understand about the use of digital technology games to aid the teaching of language, and they were keen to pursue this avenue. Participant 3 remarked:

'I read an article about the advantages of digital media and digital games. It made me realise that the continuous flow of new images on the screen keeps their attention. Because they are exposed the whole day, especially at home, to digital entertainment, this is what they are used to. It is difficult to keep their attention with traditional teaching materials. They are used to a constant flow of images on a screen.' (Participant 3, Grade R teacher, April 2018)

\section{Approaches to language teaching}

Teachers approached language teaching in different ways, and three Grade R learners were observed using digital technology. More traditional pedagogical methods such as stories, drawings, music and flashcards were used, as was the identification of rhyming words to enable the learners to acquire new words and sounds. During the semi-structured individual interviews, five of the eight teachers said that they regularly mixed their traditional pedagogical ways with technology such as tablets, cell phones, computers, projectors and screens. The other three stated that they relied more on the traditional pedagogical methods. Participant 6 said, 'I use flash cards with words and pictures. I also scan in pictures of animals, fruit, etc. to teach the learners to identify them' (Participant 1, Grade R teacher, April 2018). These images were shown on the screen and it became clear that the majority of the participating teachers of the selected school were not using digital play to enhance language acquisition. The reason provided was that there were not suitable digital games available.

\section{Beliefs about the pedagogical value of digital play}

During the focus group interview, all the teachers seemed to share the view that digital play for language acquisition has great value in terms of developing logic, communication 
skills, hand-eye coordination and skills of perception. They unanimously agreed that digital media and digital play would be sorely missed by the children if taken away. The children would feel detached and disconnected because using digital play as a pedagogical tool is a reality of the modern world.

During the non-participant classroom observations, the learners were much more engaged when digital play was used than in lessons where only traditional methods were used. This was evident where learners identified with pictures on the screen and contextualised them with their prior experiences, which they then shared with the class. Such an observation is a rudimentary use of technology and does not include the elements of a playful encounter. Teachers noted that there are no clear recommendations in the curriculum for the incorporation of digital games; let alone how to teach using such tools or pedagogies. However, they confirmed the value of digital play in the classroom.

Seven of the teachers believed that digital play is of value in language teaching as it develops communication skills and vocabulary, and the learners become more involved in the classroom activities. However, one participant did voice reservations about the benefit of digital games to aid teaching language skills. She never really tried to use digital games in her classroom as part of her teaching practice before and could not understand the value of using digital games for language acquisition if she can just as easily carry on using her traditional methods.

\section{Beliefs about digital play for the enhancement of language learning}

The teachers agreed during the focus group discussion that times have indeed changed and that they understand that teaching methods will have to adapt to the challenges of this Digital Era. They agreed there was no possibility of going back to traditional teaching methods.

During the observations of the classes, it was evident that digital games are relevant to the subjects of mathematics and life orientation, and further that they aid the teaching of language. Three teachers used digital play to integrate language teaching with the other subjects, such as mathematics, where they communicate whilst solving problems. Learners had to complete certain patterns and sequence numbers in a game on the tablet, using words such as 'longest', 'shortest', 'bigger' and 'smaller'. The Grade $\mathrm{R}$ teachers valued digital play for enhancing language teaching as it encourages learners to formulate questions, improve their vocabulary and they listen attentively whilst involved in digital play.

\section{Discussion}

The main finding is that teachers are using digital play methods to a limited extent for sound and letter recognition, pronunciation and vocabulary. Teachers seem to have a poor understanding of digital play methods but are keen to explore the potential of these methods, especially because they are used to the traditional play methods as prescribed by CAPS.

The findings of this study may be interpreted in terms of Bronfenbrenner's (1994:39) ecological framework. The researcher applied the framework in order to understand how the teachers had developed regarding the essential components of the phenomenon of this research. In terms of this framework, the teacher's world comprises five interrelated systems, and these were used to extrapolate the findings of the research. The adapted framework here (Figure 1) shows the key findings.

\section{Microsystem}

In the microsystem the teacher is at the centre, but this system also comprises all the learners at the school. The classroom is a microsystem for the teacher, and it was evident in the easy way they handled the tablets that most of the learners had prior exposure to digital technology in the home, which is another microsystem. The use of digital technology is included for lesson planning; however, digital pedagogy is not taken into consideration. Some of the children had more exposure to digital technology than others, although the home encounters with technology are supplemented by the teachers' use of digital technology in the classroom to transfer such home-based knowledge to the classroom.

\section{Mesosystem}

The mesosystem deals with the relationships in the microsystems, that is, the school, the teacher, the children and the extended family. The learners' prior knowledge of digital technology obtained at home, and the expertise of the Grade $\mathrm{R}$ teachers regarding digital play, had to be taken into consideration. For a conducive teaching environment, homeostasis using digital technology must be created by the teacher. However, it must be noted that this was used to a limited extent in this study.

\section{Exosystem}

For this research, the exosystem comprises the community around the school, the school itself and the district office of the DBE. In a way it extends the mesosystem and comprises various structures of a social nature, which have an influence on the individual. Parents are obviously not physically present at the school, but their psychological presence is important as the child's first experience of digital technology is in the home. The environment beyond the classroom comprises digital technology in every way. It is the sine qua non, and using appropriate digital pedagogies in class, especially for language teaching, connects the learners and teachers to the exosystem. 


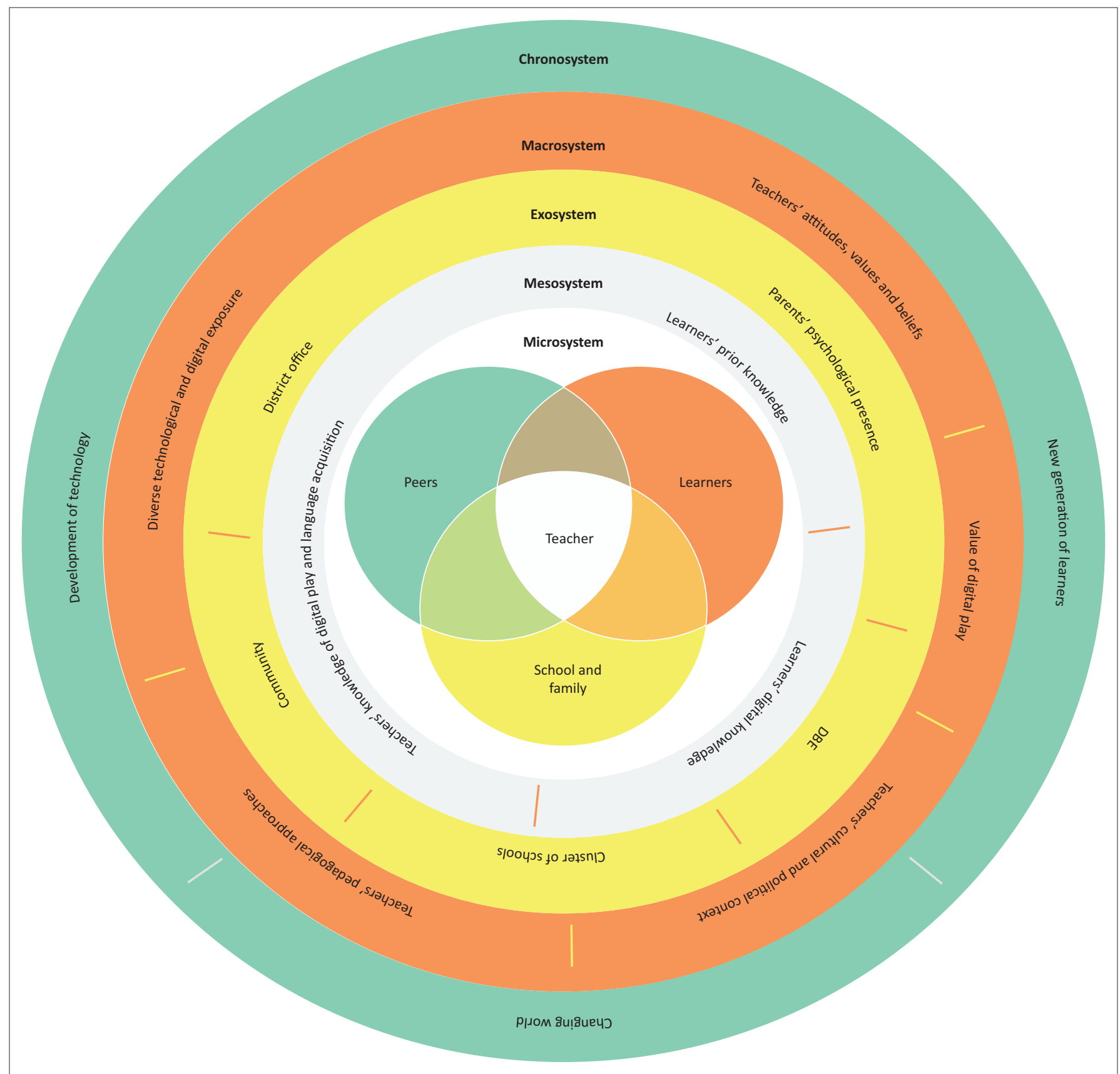

Source: Bronfenbrenner, U., 1994, 'Ecological models of human development', International Encyclopaedia of Education 3(2), 37-43.

$\mathrm{DBE}$, Department of Basic Education.

FIGURE 1: Key findings according to Bronfenbrenner's ecological framework.

\section{Macrosystem}

The macrosystem comprises the beliefs and values of the teachers, that is, their cultural and political environment. As this system moves into the Fourth Industrial Revolution and the age of artificial intelligence (AI), learners are potentially being exposed to a multitude of digital technologies. If teachers introduce digital pedagogies to extend the teaching of language teaching in Grade $\mathrm{R}$, it means that learners have early exposure to this world of technology. This research clearly illustrates the fact that young children are entirely at ease with digital technology, but unfortunately the teachers in this study are lagging behind. This seems to be a common phenomenon as the teachers might be 'digitally competent in their personal lives, a dominant ideology regarding play-based pedagogy prevented the integration of digital devices' in their teaching pedagogies (Marklund 2019:3).

\section{Chronosystem}

All of recent history, including major advances that have become the norm such as the pervasiveness of technology, are embedded in the chronosystem. The school selected for this study did have classrooms stocked with tablets as the teachers realised that digital technology, especially for play, must be incorporated into their pedagogy. However, although they use them in various lessons, they are rather 
reluctant as they are not entirely confident with digital technology. Digital technology will become more and more relevant in the learners' lives, and thus the researcher encourages teachers to use digital play when teaching language, notwithstanding the fact that it is acknowledged that there is a lack of suitable digital material and concomitant pedagogical support.

The knowledge of digital play for these Grade R teachers was in line with the findings of Murcia et al. (2018:251). These authors state that teachers must have sufficient knowledge and skills in the fundamentals of digital technology, because as Arnott (2016:271) elaborated, digital technology is a reality of the early teaching ecological system. According to the Professional Framework for Digital Learning (DBE 2018:1519), there are important indicators for the educator's digital learning proficiencies. Indicators such as understanding the role of the teacher and the digital resources during digital learning, selecting appropriate digital tools and resources to enhance learning objectives in various learning environments and transforming learning through the innovative use of digital tools and resources are applicable. The researcher set out to gauge how aware the teachers were of digital play, and then to connect this to Bronfenbrenner's (1994) chronosystem, that is, the interconnectedness of such technology for both learner and teacher. This research noted the evidence of tablets and PCs, cellphones and digital games in the form of videos and stories. These are listed by Berson and Berson (2010:3), Plowman (2015:38) and Murcia et al. (2018:251). In line with Bers (2018:104) and Snow and Matthews (2016:65), the teachers acknowledged that digital play influences the learners' understanding of phonemic analysis and furthers their social skills in terms of interaction and communication.

The finding that six teachers used digital play during the observed lessons confirmed that technology in the form of tablets, projectors and laptops is well used, but the teachers are anxious to understand exactly how the pedagogy of using such technology for language teaching and play can be used. This is in line with Bronfenbrenner's (1994) mesosystem where the teacher, the learner and the family form a unit. The data revealed that digital pedagogies and the concomitant skills to support the digital world are necessary. This is underscored by Murcia et al. (2018) who posited that proper training in the various digital technologies for teachers is a must:

The specified elements of the digital technologies with which a teacher should be competent include a knowledge and understanding of digital systems and data representations as well as the processes and production skills required to collect and manage data, and creating digital solutions to problems. (p. 251)

Parette and Blum (2013:124) concurred and strongly advocated for the inclusion of technology in the childhood development curriculum and stressed the importance for changes to pedagogical approaches. According to Parette and Blum (2013:7), because digital technologies are interactive, the teacher is able to scaffold their pedagogical approach. This research indicated that teachers have not received sufficient, if any, training in the application of digital pedagogy.

The evidence from the data are that teachers have the tendency to mix both existing and digital pedagogical approaches, and they remain willing to learn about other digital methods of teaching, specifically for teaching language. This is in accordance with Berschorner and Hutchinson (2013:17) who said that adequate literacy for all will be evident in this digital environment. Murcia et al. (2018:251) also advocated for the inclusion of a variety of digital methods to further young learners' interaction with such technology.

The teachers valued digital play for language teaching, and this is in agreement with Pepler (2015:165) as the view is that play using digital technology provides learners with many opportunities to enlarge their vocabulary and it helps with structuring a sentence and their general understanding of semantics. The data revealed that learners remember better when engaged in digital play, that is, they need to hear the sounds and see what is happening on the screen at the same time. This finding concurs with Berschorner and Hutchinson's (2013:18) view that technology enables recall, comprehension and retention. Using technology in class enhances independence and assists exploration amongst learners; however, in this study it was evident that the learners were not empowered to explore these concepts as the teachers did not encourage them to do so.

The analysis confirmed an overwhelming willingness from the teachers to expand their language teaching practices and ensure that technology is part of the pedagogical practice. New forms of social interaction and stimulation (Plowman \& McPake 2013:28) are evident in the digital world and teachers must choose appropriate technology and the necessary skills to confidently use digital technology for language learning and play.

\section{Conclusion}

Play, and especially digital play, in language learning for the Grade R learners is extremely important. A paucity of digital material and digital pedagogical support is, however, noted. New insights are provided regarding the need for growth in pedagogical approaches to enhance language teaching to meet the demands of the Digital Era, especially for Grade R learners. This Digital Era links to Bronfenbrenner's (1994) chronosystem, which highlights that the new generation of learners is comfortable with digital technology.

This empirical research further adds to the body of knowledge by providing valuable insights into the understanding of digital play, specifically for language teaching. Furthermore, the results of this research contribute to the improvement of both teaching and learning by providing an understanding of the use of digital play to enhance language learning. 


\section{Implications}

Firstly, claims from this study are only relevant if schools are equipped with digital technology and these can be freely used by the learners. Such digital devices can be shared, enabling all learners to gain experience with such technology. To assimilate into new Digital Era and the Fourth Industrial Revolution, policies should be drafted and adopted about using digital technology and concomitant pedagogies in the Grade R year curriculum. There must be guidelines to aid teachers in the use and incorporation of digital technology in both teaching and learning.

Teacher preparation programmes and digital literacy workshops are necessary, and they must address digital pedagogy to empower teachers and enhance their skills in the use of digital media and digital pedagogies. They must be aware of how to incorporate subject matter with knowledge of the digital world in order to create exciting classroom learning experiences. The researcher recommends that further studies should be conducted in more diverse environments in South Africa, thus adding to the body of knowledge on the use of digital technology and pedagogy to enhance language learning in Grade $\mathrm{R}$ in South Africa.

\section{Acknowledgements}

The authors would like to thank the teachers who participated in this study.

\section{Competing interests}

The authors declare that they have no financial or personal relationships that may have inappropriately influenced them in writing this research article.

\section{Authors' contributions}

L.M.v.d.W. and D.M.H. contributed equally to this article.

\section{Funding information}

This research received no specific grant from any funding agency in the public, commercial or not-for-profit sectors.

\section{Data availability}

Data sharing is not applicable to this article as no new data were created or analysed in this study.

\section{Disclaimer}

The views and opinions expressed in this article are those of the authors and do not necessarily reflect the official policy or position of any affiliated agency of the authors.

\section{References}

Arnott, L., 2016, 'An ecological exploration of young children's digital play: Framing children's social experiences with technologies in early childhood', Early Years 36(3), 271-288. https://doi.org/10.1080/09575146.2016.1181049

Arnott, L. (ed.), 2017, Digital technologies and learning in the early years, Sage, Los Angeles, CA.

Arnott, L., Palaiologou, I. \& Gray, C., 2019, 'Internet of toys across home and early childhood education: Understanding the ecology of the child's social world', Technology, Pedagogy and Education 28(4), 401-412. https://doi.org/10.1080/14 75939X.2019.1656667

Bers, M.U., 2018, Coding as a playground: Programming and computational thinking in the early childhood classroom, Routledge, New York, NY.

Berschorner, B. \& Hutchison, A., 2013, 'IPads as a literacy teaching tool in early childhood', International Journal of Education in Mathematics, Science and Technology 1(1), 16-24.

Berson, I.R. \& Berson, M.J., 2010, HighTech tots: Childhood in a digital world, Information Age Publishing, Inc., Charlotte, NC.

Bronfenbrenner, U., 1994, 'Ecological models of human development', International Encyclopaedia of Education 3(2), 37-43.

Brooker, L. \& Siraj-Blatchford, J., 2002, 'Click on miaow! How children of three and four years experience the nursery computer', Contemporary Issues in Early Childhood 3(2), 251-273.

Creswell, J., 1998, Qualitative inquiry and research design: Choosing among five traditions, Sage, Thousand Oaks, CA.

Department of Basic Education (DBE), 2011, National curriculum statement grades $R-12$, viewed 10 June 2018, from https://www.education.gov.za/Curriculum/ NationalCurriculumStatementsGradesR-12.aspx.

Department of Basic Education (DBE), 2018, Professional development framework for digital learning, Department of Basic Education, Pretoria.

Dietze, B. \& Kashin, D., 2013, 'Shifting views: Exploring the potential for technology integration in early childhood education programs/Changement d'opinion: Exploration du potentiel d'integration de la technologie dans les programmes d'éducation de la petite enfance', Canadian Journal of Learning and Technology/ La Revue Canadienne de l'apprentissage et de la Technologie 39(4), 1-13. https:// doi.org/10.21432/T25P4Z

Donohue, C. \& Schomburg, R., 2017, 'Technology and interactive media in early childhood programs: What we've learned from five years of research, policy, and practice', YC Young Children 72(4), 72-78.

Edwards, S., Straker, L. \& Oakey, H., 2018, Early childhood Australia: Statement on young children and digital technology, Early Childhood Australia, Canberra.

Flick, U., 2018, An introduction to qualitative research, Sage, London.

Gonzalez-Mena, J., 2011, Foundations of early childhood education: Teaching children in a diverse society, McGraw-Hill, New York, NY.

Jensen, H., Pyle, A., Zosh, J.M., Ebrahim, H.B., Scherman, A.Z., Reunamo, J. et al., 2019 Play facilitation: The science behind the art of engaging young children, The LEGO Foundation, Billund.

Leung, S.K., Choi, K.W. \& Yuen, M., 2020 'Video art as digital play for young children', British Journal of Educational Technology 51(2), 531-554. https://doi. org/10.1111/bjet.12877

Marklund, L., 2019, 'Swedish preschool teachers' perceptions about digital play in a workplace-learning context', Early years 1-15. https://doi.org/10.1080/09575 146.2019.1658065

Mayesky, M., 2014, Creative activities and curriculum for young children, Cengage Learning, Stamford, CT.

McGlynn-Stewart, M., Brathwaite, L., Hobman, L., Maguire, N. \& Mogyorodi, E., 2018, 'Open-ended apps in kindergarten: Identity exploration through digita role-play', Language and Literacy 20(4), 40-54. https://doi.org/10.20360/ langandlit29439

Murcia, M., Campbell, C. \& Aranda, G., 2018, 'Trends in early childhood education practice and professional learning with digital technologies', Pedagogika 68(3), practice and professional learning with digital technolog

Parette, H.P. \& Blum, C.H., 2013, Instructional technology in early childhood: Teaching in the digital age, Brookes Publishing Company, Baltimore, MD.

Pepler, A., 2015, Grade $R$ in perspective: An academic and practice-orientated manual for education in grade R, African Sun Media, Stellenbosch.

Plowman, L., 2015, 'Researching young children's everyday uses of technology in the family home', Interacting with Computers 27(1), 36-46. https://doi.org/10.1093/ iwc/iwu031

Plowman, L. \& McPake, J., 2013, 'Seven myths about young children and technology', Childhood Education 89(1), 27-33. https://doi.org/10.1080/00094056.2013.757490

Schwab, K., 2017, The Fourth Industrial Revolution, Random House, London.

Snow, C.E. \& Matthews, T.J., 2016, 'Reading and language in the early grades', The Future of Children 26(2), 57-74. https://doi.org/10.1353/foc.2016.0012

Yilmaz, K., 2013, 'Comparison of quantitative and qualitative research traditions: Epistemological, theoretical, and methodological differences', European Journal of Education 48(2), 311-325. https://doi.org/10.1111/ejed.12014 